RRH: Van Doren et al. $\bullet$ SPECIES LIMITS IN AN ANTPITTA

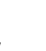

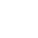

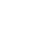

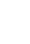

\section{SPECIES LIMITS IN THE RUSTY-BREASTED ANTPITTA (GRALLARICULA}

\author{
FERRUGINEIPECTUS) COMPLEX
}

${ }^{1}$ Department of Ecology and Evolutionary Biology, Cornell University, Ithaca, NY 14853, USA

${ }^{2}$ Edward Grey Institute, Department of Zoology, University of Oxford, Oxford, OX1 3PS, UK

${ }^{3}$ Cornell Lab of Ornithology, Cornell University, Ithaca, NY 14850, USA

${ }^{4}$ Department of Zoology, University of British Columbia, Vancouver, BC V6T1Z4, Canada

${ }^{5}$ Museum of Natural Science and Department of Natural Sciences, Louisiana State University, Baton Rouge, LA 70803, USA

${ }^{6}$ Instituto de Investigación de Recursos Biológicos Alexander von Humboldt, Villa de Leyva, Colombia

${ }^{7}$ Gimnasio Moderno, Área de Ciencias Naturales, Carrera 9 \# 74-99 Bogotá DC, Colombia

${ }^{8}$ Instituto de Zoología y Ecología Tropical, Facultad de Ciencias, Universidad Central de

Venezuela, Caracas, Venezuela

${ }^{9}$ Colección Ornitológica Phelps, Caracas, Venezuela

${ }^{10}$ Department of Organismic and Evolutionary Biology \& Museum of Comparative Zoology, Harvard University, Cambridge MA 02138, USA

${ }^{11}$ Corresponding author; email: benjamin.vandoren@zoo.ox.ac.uk.

32 Please send page proofs to the corresponding author at the above e-mail address. 
ABSTRACT.---The Rusty-breasted Antpitta (Grallaricula ferrugineipectus) is widely

34 distributed within the tropical Andes of South America. We analyzed 73 study specimens, 25

35 vouchered tissue samples and 123 audio recordings to assess geographic genetic, vocal, and

36 morphological variation and evaluate species limits. We found that Grallaricula ferrugineipectus

37 as currently defined is polyphyletic because populations from Colombia and Venezuela form a

38 clade that is closely related to Andean populations of G. nana, whereas populations from Peru

39 and Bolivia are recovered as sister to G. lineifrons. Birds in Colombia and Venezuela (the

40 northern group) last shared a common ancestor with birds from Peru and Bolivia (the southern

41 group) more than 10 million years ago. Northern and southern groups additionally differ in song,

42 suggesting that they may have evolved substantial premating reproductive isolation.

43 Discriminant function analysis reliably distinguished songs from northern and southern groups in

44 multivariate acoustic space, but univariate analyses found non-overlapping acoustic variation

45 between northern and southern groups in only one trait, mean note maximum frequency (and

46 other correlated measures of song pitch). This suggests that the "three-trait" threshold for using

47 vocalizations to inform species limits, which was developed for another suboscine group, the

48 antbirds (Thamnophilidae), may be conservative when applied to antpittas (Grallariidae). In

49 addition, we document apparent clinal variation in song pace within the southern group, a rare

50 example of a suboscine with geographic clinal variation in a vocal trait. Finally, we show that

51 northern and southern groups differ markedly in morphology. In summary, northern and southern

52 groups of Rusty-breasted Antpittas are divergent in genetics, vocalizations and morphology,

53 demonstrating that these taxa are best classified as two monophyletic, biological species with

54 allopatric distributions.

55 Keywords: Andes, clinal variation, songs, suboscine, South America, taxonomy, vocalizations 
The Rusty-breasted Antpitta (Grallaricula ferrugineipectus) is a small antpitta in the

57 family Grallariidae distributed from Venezuela to Bolivia, where it inhabits the understory of

58 humid forests in the Andes and other montane systems, such as the Sierra Nevada de Santa

59 Marta and the coastal Venezuela mountains (Hilty and Brown 1986, Krabbe and Schulenberg

60 2003, Greeney 2013). Like other Grallaricula species, G. ferrugineipectus is a plump bird with

61 long legs and a very short tail, and it is shy and seldom seen (Greeney 2013). Three subspecies

62 are currently recognized, each of which inhabits a distinct montane region: G. f. ferrugineipectus

63 is found in northern and western Venezuela and the Sierra Nevada de Santa Marta in adjacent

64 northern Colombia; G. f. rara in the Eastern Andes of Colombia and the Sierra de Perijá, which

65 straddles the Colombia-Venezuela border; and G. f. leymebambae in the Andean foothills from

66 extreme southern Ecuador to western Bolivia (Greeney 2013).

67 Current knowledge of the distribution of the species has been improved by recent

68 discoveries of populations outside its traditionally known range. Although its presence in Peru

69 north of the Marañón River had been documented since the mid 1950's based on two specimens

70 taken independently by M. Koepcke and T. A. Parker in Cancheque, Piura (Schulenberg and

71 Parker 1981, Parker et al. 1985), there are now recent records in the departments of Piura

72 (Vellinga et al. 2004) and Lambeyeque (Angulo Pratolongo et al. 2012), as well as in the

73 Ecuadorian provinces of Loja and Pichincha (Athanas and Greenfield 2016; P. Coopmans

74 unpublished data). Likewise, only in the early 1980's was the species first recorded in Bolivia

75 (Schulenberg and Remsen 1982). More recently, MAR and collaborators discovered a population

76 in the Cauca Valley of the Central Andes in the department of Caldas, Colombia; this population

77 appears to be geographically isolated from other conspecific populations. Taxonomic affinities of 
78 these populations have never been formally assessed, and their taxonomic treatment has been

79 assumed to correspond to that of the geographically closest populations.

Populations differ somewhat in elevational distribution and habitat: subspecies rara and

81 ferrugineipectus inhabit forested foothills from $\sim 250 \mathrm{~m}$ to $2200 \mathrm{~m}$ (Krabbe and Schulenberg

82 2003), and the Cauca Valley antpittas are currently known only from one locality at 1000-1100

$83 \mathrm{~m}$. Hereafter, these three populations will be referred to as the northern group. In contrast, birds

84 belonging to the southern group (populations from Ecuador, Peru, and Bolivia) range

85 substantially higher and inhabit montane forest from 1750-3350 m (Ridgely and Tudor 2009).

86 Southern group birds appear closely tied to bamboo in the genus Chusquea (Fjeldså and Krabbe

87 1990, Athanas and Greenfield 2016). This habitat association that has not been documented for

88 the northern group, which can tolerate some degree of habitat degradation (Hilty and Brown

89 1986, Niklison et al. 2008, N. Athanas pers. comm.).

90 The three subspecies of G. ferrugineipectus were described based on differences in

91 plumage and morphology. The rara subspecies is the most divergent with respect to plumage,

92 with a rich rufous-brown underside and clear rufous tones on the crown and face, in contrast to

93 the dark brown to slate-brown upperside and rufous underside of other subspecies

94 (ferrugineipectus and leymebambae). These latter two subspecies both lack rufous on the head,

95 have duller underparts, and show an obvious white throat crescent; G. f. leymebambae differs

96 from G. f. ferrugineipectus in larger size and darker overall coloration (Greeney 2013). Songs of

97 the species also vary across its geographic range. Most noticeably, G. f. leymebambae gives

98 slower and higher pitched songs than G. f. ferrugineipectus (Krabbe and Schulenberg 2003). The

99 song of G.f. rara is poorly known and not described in recent reference volumes (Krabbe and

100 Schulenberg 2003, Greeney 2013). Finally, recordings from northwest Ecuador demonstrate that 
101 this population's songs appear to be slower than those of other populations (e.g., see $\mathbf{X C 3 5 3 3 3}$

102 on xeno-canto.org).

103 Because populations of G. ferrugineipectus are distributed allopatrically throughout the

104 tropical mountains of northern South America, reproductive isolation between subspecies cannot

105 be directly assessed. Early on, systematists proposed arrangements of species level taxonomy

106 based on plumage differentiation within this complex. For example, G. f. rara was originally

107 described as a species due to its distinctive plumage (Hellmayr and Madarász 1914), while G. f.

108 leymebambae was first described as a subspecies (Carriker 1933). More recently, differences in

109 distribution, morphology, and vocalizations between G. f. leymebambae and the northern group

110 have led some authors (e.g., Ridgely and Tudor 2009, BirdLife International 2017) to classify it

111 as a distinct species. However, no formal comparative analysis has systematically examined

112 genetic, vocal, and morphological variation within this complex. These data types are

113 complementary: whereas genetic data reveal the evolutionary histories of taxa, vocalizations

114 provide information directly related to the likelihood of premating reproductive isolation (e.g.,

115 Isler et al. 1998, Zimmer 2002, Seddon and Tobias 2007, Donegan 2008, Zimmer 2008).

116 Here, we present an analysis of genetic, vocal, and morphological variation across the

117 range of G. ferrugineipectus. We construct a phylogenetic hypothesis including all named taxa

118 therein and their closest relatives to test the monophyly of the species. We then examine

119 intraspecific vocal and morphological variation and assess the diagnosability of vocal traits

120 among populations as a proxy for the level of behavioral premating isolation. With these data,

121 we ask whether populations in the northern and southern groups indeed represent different

122 species and evaluate variation in their constituent subpopulations.

123 
126 within the Grallariidae (Bravo, G. A., Cuervo, A. M., Aristizábal, N., Rice. N., Carneiro, L.,

127 Aleixo, A., Pérez-Emán, J., Brumfield, R. T. \& Bates, J. M., unpubl. data) has generated

128 mitochondrial and nuclear sequences for multiple individuals for 52 of the 53 species currently

129 recognized in the family (sensu Remsen et al. 2017). Based on preliminary phylogenetic analyses

130 of this dataset, we selected 25 grallariid individuals of the following species, which include all

131 genera in the family: Grallaria guatimalensis (1 sample), Hylopezus berlepschi (1), Myrmothera

132 campanisona (1), Grallaricula flavirostris (2), G. lineifrons (2), G. nana (7), and G.

133 ferrugineipectus (11) (Supplemental Material, Appendix 1). Five of these samples were derived

134 from toepads of museum specimens (three samples of G. ferrugineipectus rara, one sample of $G$.

135 flavirostris and one sample of G. lineifrons). This sampling encompasses all currently recognized

136 subspecies within G. ferrugineipectus and also includes birds from the Cauca Valley in

137 Colombia. However, it does not yet include samples north of the Marañón River in Peru and

138 Ecuador. For outgroups, we included sequences from the genera Scytalopus and Thamnophilus

139 (Supplemental Material, Appendix 1).

140 We used standard methods described elsewhere (Brumfield and Edwards 2007,

141 Brumfield et al. 2007, Kimball et al. 2009) to extract total DNA and to amplify and obtain 142 sequences for two mitochondrial (NADH dehydrogenase subunit 2 - ND2, 1,041 bp; and NADH 143 dehydrogenase subunit 3 - ND3, $351 \mathrm{bp}$ ) and three autosomal nuclear introns (transforming 144 growth factor- $\beta 2$ intron 5 - TGF $\beta 2,629$ bp; muscle-specific kinase receptor intron 3 - MUSK, $145651 \mathrm{bp} ; \beta$-fibrinogen intron $5-\beta \mathrm{F} 5,568 \mathrm{bp}$ ). Because toepad samples came from recent museum 
146 specimens collected in the 1990's, DNA extraction from these samples followed the same DNA

147 extraction protocols with the addition of an extended lysis time in dithiothreitol (DTT).

148 We edited sequences and checked that protein-coding sequences did not include stop

149 codons or anomalous residues using Geneious v. 8.1 (www.geneious.com, Kearse et al. 2012).

150 We aligned sequences for each marker using the MAFFT v.7 multiple alignment plugin (Katoh

151 and Standley 2013) implemented in Geneious and obtained a concatenated dataset using

152 Geneious Pro v8.1. In the end, alignments for ND2 and ND3 included sequences for all

153 individuals (27), TGFß2 (26 individuals), MUSK (25), and $\beta F 5$ (20). The final alignment

154 included data for 3,223 base pairs. Newly obtained sequences were deposited in GenBank

155 (Supplemental Material, Appendix 1).

156 Partition and Substitution Models.---We selected substitution models and the optimal

157 partitioning regime using the greedy algorithm (Lanfear et al. 2012) and PhyML v. 3.0 (Guindon

158 et al. 2010) implemented in PartitionFinder2 (Lanfear et al. 2017). We evaluated those models of

159 molecular evolution available in BEAST (Drummond et al. 2012, Bouckaert et al. 2014) and the

160 maximum number of partitions was set to be five (each marker treated separately). Using the

161 corrected Akaike Information Criterion (AICc) (Hurvich and Tsai 1989) as a model selection

162 parameter, we were able to partition data in three different subsets: ND2, ND3, and the three

163 nuclear introns.

164 Phylogenetic inference.---Using the selected partitioned scheme, we conducted a

165 maximum likelihood phylogenetic analysis with the GTR $+\Gamma$ model of nucleotide substitution and

166999 bootstrap replicates implemented in RAxML 8.2.9 (Stamatakis 2014) on the CIPRES

167 Science Gateway V 3.3 (Miller et al. 2010). We estimated a time-calibrated species tree in a

168 Bayesian framework using the multispecies coalescent model implemented in the program 
170 V 3.3. We used unlinked substitution models across partitions and clock models linked by locus

171 (i.e. mtDNA and each intron separately). Gene trees were estimated independently for each of

172 the four loci (both mtDNA markers were treated as a single locus). Substitution parameters were

173 based on results previously obtained from PartitionFinder2. Based on the avian mtDNA

174 substitution rate of 2.1\%/My (Weir and Schluter 2008), we used a lognormal relaxed molecular

175 clock with a mean rate of 0.0105 for mtDNA. Clock rates for nuclear introns were estimated

176 relative to the rate of mtDNA. We used a Yule prior with no restrictions on tree shape and a

177 randomly generated tree as a starting tree. We ran analyses for a total of 200 million generations

178 with a sampling frequency of 20,000. We determined that replicate analyses converged (effective

179 sample size values > 400) using Tracer v1.6 (Rambaut et al. 2014). Using TreeAnnotator v2.4.4

180 (Drummond et al. 2012, Bouckaert et al. 2014) and a burn-in of 20\%, we estimated a posterior

181 distribution of topologies and the maximum clade credibility (MCC) tree.

182

Morphometric data.---We measured six morphological variables (wing length, tail length,

183 tarsus length, bill length from nostril to tip, bill gape, bill depth at nostrils) from 73 study

184 specimens of all subspecies of Grallaricula ferrugineipectus (Supplemental Material, Appendix

185 2) following Baldwin et al. (1931). We measured nine specimens of G.f. ferrugineipectus

186 (including six from the Sierra Nevada de Santa Marta), six from the Cauca Valley of Colombia,

18710 from G.f. rara, and 48 of G. f. leymebambae, including one from north of the Marañon

188 Valley. All measurements were taken to the nearest $0.01 \mathrm{~mm}$ with a Mitutoyo Digimatic Point

189 Caliper by GAB.

190 Audio recordings.---We compiled recordings of Grallaricula ferrugineipectus from the

191 Macaulay Library at the Cornell Lab of Ornithology (macaulaylibrary.org), xeno-canto (xeno- 
192 canto.org), the natural sound collection of Instituto de Investigación de Recursos Biológicos

193 Alexander von Humboldt (humboldt.org.co), and private collections of recordists (Supplemental

194 Material, Appendix 3). We retained recordings that contained high-quality examples of the

195 species' song. Variation in the song of an individual is present in suboscines but is relatively

196 small (e.g., Bard et al. 2002, Kirschel et al. 2011); we confirmed that individual variation was

197 minor (at least within a single recording session) by manually inspecting vocalizations of the

198 same individual. We selected one song per individual for further analysis, typically the best-

199 recorded song in a series or the one with the least background noise. From these recordings, we

200 obtained 110 songs from as many individuals (Fig. 1): 49 of G. f. ferrugineipectus (including 13

201 from the Sierra Nevada de Santa Marta), four of G. f. rara from the Eastern Andes of Colombia,

202 five from the Cauca Valley in the Colombian Central Andes, 12 from northwest Ecuador, four

203 from the Andes between the Marañón River and central Ecuador, and 36 of G. f. leymebambae

204 south of the Marañón River. To compare vocal variation within the G. ferrugineipectus complex

205 to closely related species, we included 7 songs from G. nana and 6 from G. lineifrons in our

206 analysis, but we did not include G. flavirostris because the song of this species seems to consist

207 of only one note and thus cannot be meaningfully compared to the other species, which all have

208 multi-note songs.

209 Acoustic data processing.---We used Raven Pro 1.5 (Bioacoustics Research Program

210 2014) to make measurements of the acoustic properties of vocalizations. Grallaricula songs are

211 typically composed of a series of repeated notes that are structurally simple (Greeney 2013). It is

212 therefore straightforward to capture acoustic variation of Grallaricula vocalizations with a series

213 of acoustic measurements. For each song, we manually identified its constituent notes by

214 drawing selection boxes. We then used the Raven software to record the following measurements 
215 for each note: the frequency of peak power, the minimum and maximum frequencies of the peak

216 frequency contour, the average slope of the peak frequency contour, the duration containing $90 \%$

217 of the energy of the note, and the bandwidth containing $90 \%$ of the energy of the note. We

218 summarized these note measurements using the following 19 statistics for each song: 1) mean

219 note slope (Hz/ms), 2) mean note peak frequency (Hz), 3) mean note bandwidth (Hz), 4) mean

220 note peak frequency bandwidth $(\mathrm{Hz}), 5-6)$ mean note maximum and minimum frequencies $(\mathrm{Hz})$,

221 7) number of notes per song (note count), 8) the duration of the song (s), 9) the mean duration of

222 each note $(\mathrm{s}), 10)$ the rate of note delivery (note rate or song pace; notes per second), 11) the

223 frequency slope of the song (Hz per note), 12) the song peak frequency bandwidth (Hz), 13-14)

224 the position of the frequency minima and maxima within each note of the song (proportion of

225 note from $0-1), 15$ ) the change in note pacing through the song (s per note), 16) the maximum

226 frequency of the song $(\mathrm{Hz}), 17)$ the minimum frequency of the song $(\mathrm{Hz}), 18)$ the difference

227 between the two (song bandwidth; $\mathrm{Hz}$ ), and 19) and the position of the maximum frequency note

228 in the song (proportion of song from $0-1$ ). We subsequently examined measurements for

229 collinearity and found that measurements $2,5,6,16$, and 17 were closely correlated. Of these,

230 we retained only mean note maximum frequency (5) because it showed the highest correlations

231 with the other frequency variables (all $\mathrm{r}>0.95)$.

232 We included recordings made following the use of conspecific playback in our dataset.

233 Although most recordings did not have associated metadata describing whether they followed

234 playback or not, the vast majority of recordings with such metadata were made using playback

235 (see Supplemental Material, Appendix 3). We therefore have too few recordings made without

236 playback for each taxon to investigate a possible effect of its use at this time. However, we

237 believe that the use of playback is unlikely to affect our conclusions regarding acoustic 
238 differentiation for three reasons. First, the use of playback was relatively consistent among

239 subspecies. Second, we have no a priori reason to believe that playback differentially influences

240 different subspecies. Third, even if playback does induce vocal differences, including recordings

241 made both with and without playback provides a fuller range of vocal variation of each

242 population (i.e., calmer and agitated individuals), which is a statistically conservative approach

243 to assessing diagnosability.

244 Statistical Analyses.---We conducted several analyses to quantify levels of differentiation

245 and diagnosability in acoustic and morphological traits in our sample. We began by examining

246 differentiation between the northern and southern groups, which have been proposed to represent

247 different species (e.g., Ridgely and Tudor 2009). We first tested for differences in means of

248 vocal and morphological traits, using the Tukey Test to correct for multiple comparisons. We

249 applied a log transformation when it reduced the skewness of the given trait distribution. We

250 then calculated $95 \%$ prediction intervals for all traits, which estimate the spread of observations

251 in a population; non-overlapping prediction intervals indicate that trait distributions are unlikely

252 to overlap even as a larger sample is gathered (Isler et al. 1998). Species delimitation criteria

253 derived for another suboscine group, the antbirds, suggest that allopatric populations should be

254 classified as distinct biological species when they have diagnosable (non-overlapping)

255 differences in at least three independent vocal traits (Isler et al. 1998, Isler et al. 2007a, Isler et

256 al. 2007b, Isler et al. 2008). This yardstick approach has also been used in antpittas (Donegan

257 2008), but its efficacy has not been widely evaluated in the Grallariidae (e.g. by systematically

258 analyzing existing sympatric species pairs). As acknowledged by its proponents, this yardstick

259 approach as a point of reference (Isler et al. 1998) can be relaxed in certain cases, especially 
260 when taxa are parapatric, or show distinct morphological differentiation (Isler et al. 2007b, Isler 261 et al. 2012).

As an additional measure of diagnosability, we conducted discriminant function analyses

263 on the above groupings. We scaled and centered our data before analysis by subtracting the mean

264 and dividing by the standard deviation. We quantified diagnosability with a cross-validation

265 approach: we withheld one datum, trained the model with the remaining data, and then asked the 266 model to classify the withheld datum. We repeated this procedure 1,000 times and then

267 calculated a misclassification rate for each taxonomic grouping. We analyzed vocal and

268 morphological data separately because our vocal and morphological measurements were made

269 on different individuals.

270 In addition, we tested for geographic variation within northern and southern groups in

271 vocal and morphological traits. Within the northern group, we examined four subpopulations: 1)

272 G.f. ferrugineipectus from Venezuela, 2) G. f. ferrugineipectus from the Sierra Nevada de Santa

273 Marta, 3) G. f. rara from the Eastern Andes of Colombia, and 4) the population from the Cauca

274 Valley of the Colombian Central Andes. We treated the population from the Sierra Nevada de

275 Santa Marta as a distinct group to test for differentiation due to their isolated distribution. Within

276 the southern group, we considered two subgroups: 1) antpittas from Ecuador and northwestern

277 Peru, which are vocally similar (P. Coopmans, unpubl. data), hereafter "northern leymebambae;

278 and 2) antpittas from northeastern Peru south (hereafter "southern leymebambae"). These groups

279 are divided by the Marañon River, an important isolating barrier for Andean avifauna (Winger

280 and Bates 2015). We primarily used discriminant function analyses as described above, but we

281 also conducted tests of the " $75 \%$ rule," which is satisfied if $75 \%$ of the trait values for a

282 population lie outside $99 \%$ of the trait values of the other population (Patten et al. 2002). This 
283 test has previously been used as a criterion for subspecies classification in the genus Grallaricula

284 (Donegan 2008).

\section{RESULTS}

Phylogenetic analyses.---Maximum-likelihood and Bayesian analyses produced identical

287 topologies supporting the non-monophyly of Grallaricula ferrugineipectus. Northern

288 populations (i.e., G.f.ferrugineipectus, G. f. rara, Cauca Valley, and Sierra Nevada de Santa

289 Marta) form a strongly supported clade that is sister to Andean populations of G. nana (albeit

290 with low support in the Bayesian species tree), whereas populations from Peru and Bolivia (i.e.,

291 G. f. leymebambae) are recovered as sister to G. lineifrons (Figs. 2 and 3). The time-calibrated

292 species tree estimated that the most recent common ancestor between northern and southern

293 groups split between 10.8 and 16.8 mya (Fig. 3). Additionally, northern populations of $G$.

294 ferrugineipectus exhibit some degree of geographic structure and differentiation that is not

295 entirely consistent with current subspecific boundaries. Further insights regarding taxonomic

296 limits of northern populations and their close relationship with G. nana will be published

297 elsewhere.

298 Overall vocal variation.---Northern and southern groups show strong divergence in song

299 (Fig. 4). To visualize these differences, we plotted the first two factors of a DFA run on all

300 populations (Fig. 5). The first factor, which explained $86.7 \%$ of between-group variance, loaded

301 strongly for mean note maximum frequency and song pace (Fig. 6). The second factor, which

302 explained $9.3 \%$ of the variance, was primarily composed of the number of notes per song and

303 additional variation in song pace (Supplemental Material, Table S1).

304 Overall morphological variation.---We visualized divergence in morphometrics in the

305 same way as for vocal variation (Fig. 7). The first factor explained $85.6 \%$ of the variance 
between measured populations and loaded strongly for tarsus, tail length, and wing length. The

307 second factor, which explained $9.3 \%$ of the variance, was primarily composed of bill length and

308 gape (Supplemental Material, Table S2).

309 Tests of species rank.---Northern and southern groups significantly differed in the mean

310 values of 13 out of 15 vocal traits (Supplemental Material, Fig. S1). However, mean note

311 maximum frequency was the only vocal character for which $95 \%$ prediction intervals did not

312 overlap (Table 1). To place this result into context, we considered the number of vocal characters

313 for which 95\% prediction intervals did not overlap between currently recognized Grallaricula

314 species. The southern group differed from G. nana in only one vocal character, song pace,

315 whereas populations in the northern group differed from G. nana in three characters: mean note

316 maximum frequency, the frequency slope of the song, and the position of the maximum

317 frequency in the song. Both northern and southern groups differed from G. lineifrons by several

318 vocal traits (seven and four, respectively), and G. nana differed from G. lineifrons by eight vocal

319 traits (Table 1). Although northern and southern groups differed significantly from one another

320 in the mean value of all six morphological characters (Supplemental Material, Fig. S2), none was

321 diagnosable at the $95 \%$ prediction level.

322 Discriminant function analysis performed well at separating northern and southern groups

323 based on both vocal and morphological traits. For vocal traits, the cross-validated correct

324 classification rate was 100\% for the northern group and $97.6 \%$ for the southern group. The single

325 discriminant factor loaded most heavily for mean note maximum frequency (Supplemental

326 Material, Table S3). For morphological traits, the cross-validated correct classification rate was

$32795.5 \%$ for the northern group and $100 \%$ for the southern group; the discriminant factor was

328 primarily composed of tarsus and tail length (Supplemental Information, Table S4). 
330 exhibited significant variation in mean vocal trait values, with 12 of 15 traits showing significant

331 differences among populations (Supplemental Material, Fig. S3). However, discriminant analysis

332 showed a relatively poor ability to distinguish northern populations based on vocal traits. The

333 most distinctive populations were G. f. ferrugineipectus from Venezuela and the population from

334 the Cauca Valley of Colombia, which were classified with 85.1 and $82.6 \%$ accuracy,

335 respectively. Songs from the Sierra Nevada de Santa Marta were classified with 78.0\% accuracy

336 and from the subspecies rara with $76.9 \%$ accuracy. The first discriminant factor $(72.4 \%$ of

337 variance) loaded very strongly for song pace and number of notes, and the second (19.1\%) for

338 additional variation in song pace (Supplemental Material, Table S5). By the 75\% rule, these four

339 populations were generally not diagnosable; G. f. rara from the Eastern Andes of Colombia

340 differed from G.f. ferrugineipectus from Venezuela in song pace, but this was the only

341 difference among northern populations.

342 Populations from the northern group showed significant differences in mean values of

343 four morphological traits (Supplemental Material, Fig. S4), but there were no differences at the

344 level of the $75 \%$ rule. The discriminant analysis of morphological traits performed poorly at

345 distinguishing G. f. ferrugineipectus from Venezuela (20.9\% correct), G. f. rara (51.1\% correct),

346 and individuals from the Cauca Valley (65\% correct) (Supplemental Material, Table S6),

347 whereas those from the Sierra Nevada de Santa Marta achieved a correct classification rate of

$34876.8 \%$. Note, however, that the sample sizes for these groups were generally small $(\mathrm{N}=3-8)$.

349 Geographic variation within the southern group.---Southern Rusty-breasted Antpitta

350 populations also varied in mean vocal trait values, with significant differences between northern

351 and southern leymebambae in 8 of 15 traits (Supplemental Material, Fig. S5). Discriminant 
352 analysis performed well in distinguishing the two groups, with cross-validated correct

353 classification rates of $95.5 \%$ and $97.2 \%$ for northern and southern leymebambae, respectively.

354 The single discriminant factor (100\% of variance) loaded strongly for the number of notes per

355 song, song duration, and song pace (Supplemental Material, Table S7). Considering the 75\% test,

356 however, the groups showed no diagnosable vocal differences. Morphological tests were not

357 conducted because there was only one measured individual from the "northern leymebambae" 358 group.

\section{DISCUSSION}

We find that Grallaricula ferrugineipectus, as currently recognized, is polyphyletic. The

362 southern subspecies G. f. leymebambae is more closely related to G. lineifrons and G. flavirostris

363 than it is to the northern subspecies G.f. ferrugineipectus and G. f. rara; in turn, these northern

364 populations are more closely related to G. nana than to G. f. leymebambae. In fact, the split

365 between the northern and southern clades represents the earliest divergence within the genus

366 Grallaricula (Fig. 2, Bravo et al. unpubl. data), and the age of this split is close to the start of

367 diversification of the Hylopezus-Myrmothera-Gallaricula clade, estimated at approximately 13-

36821 mya (Ohlson et al. 2013). Hence, G. ferrugineipectus, as currently defined, is polyphyletic

369 and comprises populations that belong to highly divergent and distinctive clades. We therefore

370 propose to elevate G. f. leymebambae to species rank. We recommend the complex be

371 considered to consist of two species and, provisionally, two subspecies.

372

373

Grallaricula ferrugineipectus (Sclater 1857)

374

Grallaricula f. ferrugineipectus (Sclater 1857) 
Hereafter, we refer to these taxa by the above naming scheme.

Taxonomic status and nomenclature of the populations in the Cauca Valley of Colombia

382 and north of the Marañón River in Peru and Ecuador will be assessed elsewhere. Here, they are

383 maintained as part of G. ferrugineipectus and G. leymebambae, respectively, with no defined

384 subspecific ascription.

385 Even though the split between G. ferrugineipectus and G. leymebambae was one of the 386 earliest divergence events in Grallaricula, these allopatric taxa were diagnosable at the $95 \%$

387 prediction level in only one measured vocal trait, the mean note maximum frequency, and in no 388 measured morphological traits. In addition, G. leymebambae differed from G. nana by only one 389 vocal character, song pace. In contrast, G. ferrugineipectus differs from G. nana by three vocal 390 characters. A point of reference of diagnosability in at least three vocal traits for species status 391 has been frequently used in suboscine taxonomy, traditionally with antbirds (Isler et al. 1998, 392 Isler et al. 2007a, Isler et al. 2007b, Isler et al. 2008) but also in antpittas (Donegan 2008). The 393 results of the present study suggest that this framework, which does not consider how multiple 394 traits covary among populations, may be conservative when applied to allopatric antpitta taxa. 395 For example, the northern and southern groups did not differ in song pace at the 95\% prediction 396 level, but the combination of song pace and note frequency yielded fully distinguishable groups 397 (Figs. 5 and 6). Further assessment of the "three-trait" rule is still required for the Grallariidae. 
398 We emphasize that, though diagnosably different in only a single measured vocal trait, songs

399 from northern and southern groups were fully distinguishable in our multivariate discriminant

400 function analyses. Other differences may also be present in calls, which we did not examine here.

401 Divergence in vocal traits can in part be a by-product of changes in body size, with larger

402 birds emphasizing lower-pitched sounds (Ryan and Brenowitz 1985, Martin et al. 2011). The

403 primary vocal difference between G. ferrugineipectus and G. leymebambae was in frequency,

404 with ferrugineipectus singing lower-pitched songs. However, morphological measurements

405 (tarsus, tail, and wing) showed that ferrugineipectus were generally smaller overall, which is a

406 difference in the opposite direction than that expected by body size alone. This suggests that the

407 primary vocal difference between these groups may be due to selection (e.g. linked to habitat or

408 sexual selection).

409 We conducted additional analyses to investigate variation in vocalizations and

410 morphology within G. ferrugineipectus and G. leymebambae. As expected, levels of

411 differentiation were generally lower within than between these groups. We found that northern

412 populations could be vocally distinguished with moderately high accuracy $(>75 \%)$, but none of

413 them could be reliably classified with morphological measurements. By the $75 \%$ rule, none of

414 these groups showed consistent differences in vocal or measured morphological traits. The small

415 sample sizes of G.f. rara and Cauca Valley songs make it difficult to reliably evaluate vocal

416 differences for these groups. Overall, moderate vocal differentiation exists across northern

417 populations, but measured morphological variation is less evident. We note that, though some of

418 these populations (e.g., G. f. rara) show divergent plumage, we did not analyze plumage

419 variation. It is interesting to note that rara did not show particularly distinct vocalizations,

420 despite distinctive plumage. 
We documented moderate vocal differentiation in Grallaricula leymebambae, with

422 northern and southern leymebambae distinguishable with 95-97\% accuracy. Song pace and

423 number of notes were the most important distinguishing variables; southernmost birds sang

424 almost twice as fast as did the northernmost birds. This trait appears to vary clinally, with no

425 evidence for distinct jumps in trait value with latitude (Fig. 8). Although previous work has

426 documented clinal variation in morphology in tropical Andean birds (e.g., Graves 1991),

427 examples of clines in suboscine song traits has seldom been noted (but see Isler et al. (2005),

428 who demonstrated clinal variation in song pace in the Variable Antshrike Thamnophilus

429 caurelescens). Given that vocal traits are presumed to be innate in suboscines, observed vocal

430 clines should reflect underlying genetic clines in the gene(s) and/or regulatory regions that

431 influence the clinal vocal trait (see Isler et al. 2005), and they potentially offer a case example to

432 investigate the genetic basis of suboscine song. However, there are additional potential barriers

433 to dispersal through the species' range (e.g., the Huallaga and Apurímac valleys; Winger et al.

434 2015), and further research is necessary to rigorously evaluate whether latitudinal patterns in

435 song pace in the southern population are truly clinal or instead show a step-wise pattern of

436 variation.

437 Our results support the well-documented role of Andean geographic features (i.e., valleys

438 and ridges) in driving and maintaining population structure of Andean birds (e.g., Gutiérrez-

439 Pinto et al. 2012, Benham et al. 2015, Winger and Bates 2015). Specifically, features such as the

440 Maranon valley in northern Peru and the Cauca and Magdalena valleys in the Northern Andes

441 have been widely supported as primary barriers to dispersal in the Andes (Vuilleumier 1969,

442 Parker et al. 1985, Fjeldså and Krabbe 1990, Weir 2009, Cuervo 2013, Winger and Bates 2015).

443 These valleys act as pronounced barriers for antpittas and have likely shaped observed patterns 
444 of phylogeographic structure within both $G$. ferrugineipectus and G. leymebambae. It is also

445 important to note that the apparently disjunct range of G. ferrugineipectus sensu lato-with a

446 large gap in distribution between northern Ecuador and central Colombia — is an artifact of

447 taxonomic bias. As this study shows, the populations to the north and south of this "gap" (i.e. G.

448 ferrugineipectus and G. leymebambae) are not closely related. In fact, the "gap" is largely

449 occupied by their respective sister taxa, G. nana and G. lineifrons. Truly disjunct ranges in

450 Neotropical mountain birds are uncommon, and such distributions may indicate a need for

451 taxonomic revision.

452 In sum, we demonstrate that northern and southern populations of Grallaricula

453 ferrugineipectus sensu lato are 1) deeply divergent genetically, and not even sister lineages, 2)

454 differ markedly in song (particularly in song pace), and 3) are morphologically divergent. As

455 such, these two groups merit classification as distinct biological species. We further document

456 variation within each group, laying the groundwork for future taxonomic assessments. In

457 particular, further work could incorporate both genetic data and playback experiments to "ask the

458 birds themselves" if the differences in note shape and pacing between southern populations are

459 sufficient to generate premating reproductive isolation based on voice (e.g., Seddon and Tobias

460 2007, Zimmer 2008, Areta and Pearman 2009, Pegan et al. 2015).

\section{ACKNOWLEGEMENTS}

463 This analysis would not be possible without the efforts of many recordists who have contributed

464 their field recordings of Rusty-breasted Antpitta songs to the Macaulay Library of Natural

465 Sounds and xeno-canto.org and provided private recordings, including: R. Ahlman, F. Angulo, J.

466 Areta, N. Athanas, R. Behrstock, P. Boesman, P. Coopmans, S. Córdoba, O. Cortés, M. Dehling, 
467 F. Deroussen, D. Edwards, D. Geale, C. Hanks, M. Harvey, J. Hornbuckle, R. Innes, J. King, N. 468 Krabbe, F. Lambert, D. Lane, H. Lloyd, L. Macaulay, H. Matheve, J. McGowan, J. Nilsson, M. 469 Robbins, M. Sarver, F. Schmitt, T. Schulenberg, P. Schwartz, D. Stejskal, A. Spencer, H. van 470 Oosten, T. Valqui, B. Whitney, S. Woods, and K. Zimmer. We thank both these recordists and 471 the curators who maintain these collections. Likewise, we are indebted to curators, collection 472 managers, and staff of museum collections (See Appendices) for allowing access to study 473 specimens and vouchered tissue samples under their care, particularly to D. López, J. D.

474 Palacios, Ana María Umaña, Fernando Forero, Socorro Sierra, and Diego Perico (IAvH), F. G. 475 Stiles (ICN), Miguel Lentino and Margarita Martínez (COP), and S. Cardiff, D. Dittmann, R. T. 476 Brumfield, and J. V. Remsen Jr. (LSUMNS). We especially thank M. L. Isler and N. Athanas for 477 facilitating the access to recordings in private collections and for feedback on our ideas. P. 478 Salaman assisted in providing an unpublished manuscript by P. Coopmans. We thank T. 479 Schulenberg and three anonymous reviewers for helpful feedback. BVD was supported by the 480 Marshall Aid Commemoration Commission. BGF acknowledges support from the National 481 Science Foundation for Graduate Research Fellowship, Award No. 2011083591 and Postdoctoral 482 Fellowship in Biology, Award No. 1523695. Molecular and morphological work were supported 483 by grants from the LSUMNS Big Day Fund, LSU Biograds, and the National Science 484 Foundation (DEB-1011435) to GAB.

Angulo Pratolongo, F., J. N. Flanagan, W.-P. Vellinga, and N. Durand. 2012. Notes on the birds

\section{LITERATURE CITED} of Laquipampa Wildlife Refuge, Lambayeque, Peru. Bulletin of the British Ornithologists' Club 132:162-174. 
Areta, J. I., and M. Pearman. 2009. Natural history, morphology, evolution, and taxonomic status of the Earthcreeper Upucerthia saturatior (Furnariidae) from the Patagonian forests of South America. The Condor 111:135-149.

Athanas, N., and P. J. Greenfield. 2016. Birds of Western Ecuador: A Photographic Guide. Princeton University Press, Princeton.

Baldwin, S., H. Oberholser, and L. Worley. 1931. Measurements of birds. Volume II. Scientific Publications of the Cleveland Museum of Natural History, Cleveland, Ohio.

Bard, S. C., M. Hau, M. Wikelski, and J. C. Wingfield. 2002. Vocal distinctiveness and response to conspecific playback in the Spotted Antbird, a Neotropical suboscine. The Condor 104:387-394.

Benham, P. M., A. M. Cuervo, J. A. McGuire, and C. C. Witt. 2015. Biogeography of the Andean metaltail hummingbirds: contrasting evolutionary histories of tree line and habitat - generalist clades. Journal of Biogeography 42:763-777.

Bioacoustics Research Program. 2014. Raven Pro: Interactive sound analysis software (Version 1.5). The Cornell Lab of Ornithology, Ithaca, NY.

BirdLife International. 2017. Species factsheet: Grallaricula leymebambae. Downloaded from http://www.birdlife.org/.

BirdLife International and NatureServe. 2015. Bird species distribution maps of the world. Version 5.0, BirdLife International, Cambridge, UK and NatureServe, Arlington, USA.

Bouckaert, R., J. Heled, D. Kühnert, T. Vaughan, C.-H. Wu, D. Xie, M. A. Suchard, A. Rambaut, and A. J. Drummond. 2014. BEAST 2: a software platform for Bayesian evolutionary analysis. PLoS Comput Biol 10:e1003537. 
513 Brumfield, R. T., and S. V. Edwards. 2007. Evolution into and out of the Andes: a Bayesian

$514 \quad$ analysis of historical diversification in Thamnophilus antshrikes. Evolution 61:346-367.

515 Brumfield, R. T., J. G. Tello, Z. Cheviron, M. D. Carling, N. Crochet, and K. V. Rosenberg.

516 2007. Phylogenetic conservatism and antiquity of a tropical specialization: army-ant-

517 following in the typical antbirds (Thamnophilidae). Molecular phylogenetics and

$518 \quad$ evolution $45: 1-13$.

519 Carriker, M. A. 1933. Descriptions of New Birds from Peru, with Notes on Other Little-Known

520 Species. Proceedings of the Academy of Natural Sciences of Philadelphia 85:1-38.

521 Cuervo, A. M. 2013. Evolutionary Assembly of the Neotropical Montane Avifauna. Louisiana

$522 \quad$ State University Doctoral Dissertations.

523 Donegan, T. M. 2008. Geographical variation in Slate-crowned Antpitta Grallaricula nana, with 524 two new subspecies from Colombia and Venezuela. Bull Brit. Orn. Cl 128:150-178.

525 Drummond, A. J., M. A. Suchard, D. Xie, and A. Rambaut. 2012. Bayesian phylogenetics with 526 BEAUti and the BEAST 1.7. Molecular biology and evolution 29:1969-1973.

527 Fjeldså, J., and N. Krabbe. 1990. Birds of the high Andes: a manual to the birds of the temperate 528 zone of the Andes and Patagonia, South America. Zoological Museum, University of 529 Copenhagen, Copenhagen, Denmark.

530 Graves, G. R. 1991. Bergmann's rule near the equator: latitudinal clines in body size of an 531 Andean passerine bird. Proceedings of the National Academy of Sciences 88:2322-2325.

532 Greeney, H. F. 2013. Rusty-breasted Antpitta (Grallaricula ferrugineipectus) in T. S.

533 Schulenberg, editor. Neotropical Birds Online. Cornell Lab of Ornithology, Ithaca. 
534 Guindon, S., J.-F. Dufayard, V. Lefort, M. Anisimova, W. Hordijk, and O. Gascuel. 2010. New

535 algorithms and methods to estimate maximum-likelihood phylogenies: assessing the 536 performance of PhyML 3.0. Systematic biology 59:307-321.

537 Gutiérrez-Pinto, N., A. M. Cuervo, J. Miranda, J. L. Pérez-Emán, R. T. Brumfield, and C. D. 538 Cadena. 2012. Non-monophyly and deep genetic differentiation across low-elevation 539 barriers in a Neotropical montane bird (Basileuterus tristriatus; Aves: Parulidae). $540 \quad$ Molecular phylogenetics and evolution 64:156-165.

541 Hellmayr, E., and J. Madarász. 1914. Description of a new Formicarian-bird from Columbia. $542 \quad$ Annales Musei Nationalis Hungarici 12:88.

543 Hilty, S. L., and W. L. Brown. 1986. A guide to the birds of Colombia. Princeton University $544 \quad$ Press, Princeton, New Jersey.

545 Hurvich, C. M., and C.-L. Tsai. 1989. Regression and time series model selection in small $546 \quad$ samples. Biometrika:297-307.

547 Isler, M. L., A. M. Cuervo, G. A. Bravo, and R. T. Brumfield. 2012. An integrative approach to 548 species-level systematics reveals the depth of diversification in an Andean thamnophilid, 549 the Long-tailed Antbird. The Condor 114:571-583.

550 Isler, M. L., P. R. Isler, and R. T. Brumfield. 2005. Clinal variation in vocalizations of an antbird 551 (Thamnophilidae) and implications for defining species limits. The Auk 122:433-444.

552 Isler, M. L., P. R. Isler, and B. M. Whitney. 1998. Use of vocalizations to establish species limits 553 in antbirds (Passeriformes: Thamnophilidae). The Auk 115:577-590.

554 Isler, M. L., P. R. Isler, and B. M. Whitney. 2007a. Species limits in antbirds (Thamnophilidae): 555 the Warbling Antbird (Hypocnemis cantator) complex. The Auk 124:11-28. 
Isler, M. L., P. R. Isler, and B. M. Whitney. 2008. Species limits in antbirds (Aves:

Passeriformes: Thamnophilidae): an evaluation of Plumbeous Antvireo (Dysithamnus plumbeus) based on vocalizations. Zootaxa 1726:60-68.

Isler, M. L., P. R. Isler, B. M. Whitney, and K. J. Zimmer. 2007b. Species limits in the "Schistocichla" complex of Percnostola antbirds (Passeriformes: Thamnophilidae). Wilson Journal of Ornithology 119:53-70.

Katoh, K., and D. M. Standley. 2013. MAFFT multiple sequence alignment software version 7: improvements in performance and usability. Molecular biology and evolution 30:772-780.

Kearse, M., R. Moir, A. Wilson, S. Stones-Havas, M. Cheung, S. Sturrock, S. Buxton, A. Cooper, S. Markowitz, and C. Duran. 2012. Geneious Basic: an integrated and extendable desktop software platform for the organization and analysis of sequence data. Bioinformatics 28:1647-1649.

Kimball, R. T., E. L. Braun, F. K. Barker, R. C. Bowie, M. J. Braun, J. L. Chojnowski, S. J. Hackett, K.-L. Han, J. Harshman, and V. Heimer-Torres. 2009. A well-tested set of primers to amplify regions spread across the avian genome. Molecular phylogenetics and evolution 50:654-660.

Kirschel, A. N. G., M. L. Cody, Z. T. Harlow, V. J. Promponas, E. E. Vallejo, and C. E. Taylor. 2011. Territorial dynamics of Mexican Ant-thrushes Formicarius moniliger revealed by individual recognition of their songs. Ibis 153:255-268.

Krabbe, N. K., and T. S. Schulenberg. 2003. Rusty-breasted Antpitta (Grallaricula ferrugineipectus) in J. del Hoyo, A. Elliott, J. Sargatal, D. A. Christie, and E. de Juana, editors. Handbook of the Birds of the World Alive. Lynx Edicions, Barcelona. 
578 Lanfear, R., B. Calcott, S. Y. Ho, and S. Guindon. 2012. PartitionFinder: combined selection of partitioning schemes and substitution models for phylogenetic analyses. Molecular biology and evolution 29:1695-1701.

Lanfear, R., P. B. Frandsen, A. M. Wright, T. Senfeld, and B. Calcott. 2017. PartitionFinder 2: new methods for selecting partitioned models of evolution for molecular and morphological phylogenetic analyses. Molecular biology and evolution 34:772-773.

Martin, J. P., S. M. Doucet, R. C. Knox, and D. J. Mennill. 2011. Body size correlates negatively with the frequency of distress calls and songs of Neotropical birds. Journal of Field Ornithology 82:259-268.

Miller, M. A., W. Pfeiffer, and T. Schwartz. 2010. Creating the CIPRES Science Gateway for inference of large phylogenetic trees. Pages 1-8 in Gateway Computing Environments Workshop (GCE), 2010. Ieee.

Niklison, A. M., J. I. Areta, R. A. Ruggera, K. L. Decker, C. Bosque, and T. E. Martin. 2008. Natural history and breeding biology of the Rusty-breasted Antpitta (Grallaricula ferrugineipectus). The Wilson Journal of Ornithology 120:345-352.

Ohlson, J. I., M. Irestedt, P. G. Ericson, and J. Fjeldså. 2013. Phylogeny and classification of the New World suboscines (Aves, Passeriformes). Zootaxa 3613:1-35.

Parker, T., T. S. Schulenberg, G. R. Graves, and M. J. Braun. 1985. The avifauna of the Huancabamba region, northern Peru. Pages 169-197 in P. Buckley, M. Foster, E. Morton,

R. Ridgely, and F. Buckley, editors. Ornithological Monographs no. 36: Neotropical Ornithology. American Ornithologists' Union, Washington, DC.

Patten, M. A., P. Unitt, and F. Sheldon. 2002. Diagnosability versus mean differences of Sage Sparrow subspecies. The Auk 119:26-35. 
Pegan, T. M., R. B. Rumelt, S. A. Dzielski, M. M. Ferraro, L. E. Flesher, N. Young, A. Class Freeman, and B. G. Freeman. 2015. Asymmetric response of Costa Rican White-breasted Wood-wrens (Henicorhina leucosticta) to vocalizations from allopatric populations. PLoS ONE 10:e0144949.

Rambaut, A., M. A. Suchard, D. Xie, and A. J. Drummond. 2014. Tracer v1.6. Available from http://beast.bio.ed.ac.uk/Tracer.

Remsen, J. V., Jr., J. I. Areta, C. D. Cadena, S. Claramunt, A. Jaramillo, J. F. Pacheco, J. PérezEmán, M. B. Robbins, F. G. Stiles, D. F. Stotz, and K. J. Zimmer. 2017. A classification of the bird species of South America. American Ornithologists' Union. http://www.museum.lsu.edu/ Remsen/SACCBaseline.htm.

Ridgely, R. S., and G. Tudor. 2009. Field guide to the songbirds of South America: the passerines. University of Texas Press, Austin, Texas.

Ryan, M. J., and E. A. Brenowitz. 1985. The Role of Body Size, Phylogeny, and Ambient Noise in the Evolution of Bird Song. The American Naturalist 126:87-100.

Schulenberg, T., and J. Remsen. 1982. Eleven bird species new to Bolivia. Bulletin of the British Ornithologists' Club 102:52-57.

Schulenberg, T. S., and T. A. Parker. 1981. Status and distribution of some northwest Peruvian birds. Condor 83:209-216.

Sclater, P. L. 1857. Descriptions of Twelve New or Little - known Species of the South American Family Formicariidæ. Pages 129-133 in Proceedings of the zoological Society of London. Wiley Online Library.

Seddon, N., and J. A. Tobias. 2007. Song divergence at the edge of Amazonia: an empirical test of the peripatric speciation model. Biological Journal of the Linnean Society 90:173-188. 
624 Stamatakis, A. 2014. RAxML version 8: a tool for phylogenetic analysis and post-analysis of $625 \quad$ large phylogenies. Bioinformatics 30:1312-1313.

626 Vellinga, W.-P., J. N. Flanagan, and T. R. Mark. 2004. New and interesting records of birds from 627 Ayabaca province, Piura, north-west Peru. Bulletin of the British Ornithologists' Club 124:124-142.

629 Vuilleumier, F. 1969. Pleistocene speciation in birds living in the high Andes. Nature 223:11791180.

631 Weir, J., and D. Schluter. 2008. Calibrating the avian molecular clock. Molecular Ecology $17: 2321-2328$.

633 Weir, J. T. 2009. Implications of genetic differentiation in Neotropical montane forest birds.

634 Annals of the Missouri Botanical Garden 96:410-433.

635 Winger, B. M., and J. M. Bates. 2015. The tempo of trait divergence in geographic isolation:

636 Avian speciation across the Marañon Valley of Peru. Evolution 69:772-787.

637 Winger, B. M., P. A. Hosner, G. A. Bravo, A. M. Cuervo, N. Aristizábal, L. E. Cueto, and J. M.

638 Bates. 2015. Inferring speciation history in the Andes with reduced-representation

639 sequence data: an example in the bay-backed antpittas (Aves; Grallariidae; Grallaria 640 hypoleuca s. 1.). Molecular Ecology 24:6256-6277.

641 Zimmer, K. J. 2002. Species limits in Olive-backed Foliage-Gleaners (Automolus: Furnariidae). The Wilson Bulletin 114:20-37.

643 Zimmer, K. J. 2008. The White-eyed Foliage-gleaner (Furnariidae: Automolus) is two species. 644 The Wilson Journal of Ornithology 120:10-25. 
647 Table 1. Vocal traits that differ between northern and southern Rusty-breasted Antpittas and two 648 congeners following the $95 \%$ prediction interval test.

\begin{tabular}{|c|c|c|c|c|}
\hline & north & \multicolumn{2}{|l|}{ nana } & lineifrons \\
\hline south & MNMX & \multicolumn{2}{|l|}{ RND } & MNMX FSS SPFB SB \\
\hline north & & \multicolumn{2}{|c|}{ MNMX FSS PHFN } & $\begin{array}{l}\text { MNMX DS MDN RND } \\
\text { FSS SPFB SB }\end{array}$ \\
\hline nana & & & & $\begin{array}{l}\text { MNPFB MNB DS } \\
\text { MDN RND FSS SPFB } \\
\text { PHFN }\end{array}$ \\
\hline \multicolumn{3}{|c|}{ Mean note slope $(\mathrm{Hz} / \mathrm{ms})$} & \multicolumn{2}{|c|}{ MNS } \\
\hline \multicolumn{3}{|c|}{ Mean note peak frequency $(\mathrm{Hz})$} & \multicolumn{2}{|c|}{ MNPF } \\
\hline \multicolumn{3}{|c|}{ Mean note peak frequency bandwidth $(\mathrm{Hz})$} & \multicolumn{2}{|c|}{ MNPFB } \\
\hline \multicolumn{3}{|c|}{ Mean note bandwidth $(\mathrm{Hz})$} & \multicolumn{2}{|c|}{$\mathrm{MNB}$} \\
\hline \multicolumn{3}{|c|}{ Mean note maximum frequency $(\mathrm{Hz})$} & \multicolumn{2}{|c|}{ MNMX } \\
\hline \multicolumn{3}{|c|}{ Mean note minimum frequency $(\mathrm{Hz})$} & \multicolumn{2}{|c|}{ MNMN } \\
\hline \multicolumn{3}{|c|}{ Number of notes per song } & \multicolumn{2}{|c|}{ NNS } \\
\hline \multicolumn{3}{|c|}{ Duration of song (s) } & \multicolumn{2}{|c|}{ DS } \\
\hline \multicolumn{3}{|c|}{ Mean duration of each note (s) } & \multicolumn{2}{|c|}{ MDN } \\
\hline \multicolumn{3}{|c|}{ Rate of note delivery (notes per s) } & \multicolumn{2}{|c|}{ RND } \\
\hline \multicolumn{3}{|c|}{ Frequency slope of the song (Hz per note) } & \multicolumn{2}{|c|}{ FSS } \\
\hline \multicolumn{3}{|c|}{ Song peak frequency bandwidth $(\mathrm{Hz})$} & \multicolumn{2}{|c|}{ SPFB } \\
\hline \multicolumn{3}{|c|}{ Position of the frequency min within each note } & \multicolumn{2}{|c|}{ PFMN } \\
\hline \multicolumn{3}{|c|}{ Position of the frequency max within each note } & \multicolumn{2}{|c|}{ PFMX } \\
\hline \multicolumn{3}{|c|}{ Change in pace (s per note) } & \multicolumn{2}{|c|}{$\mathrm{CP}$} \\
\hline \multicolumn{3}{|c|}{ Maximum frequency of the song $(\mathrm{Hz})$} & MX & \\
\hline Minir & frequency & $\mathrm{g}(\mathrm{Hz})$ & MN & \\
\hline Song & dwidth $(\mathrm{H}$ & & SB & \\
\hline Positi & f the high & cy note & $\mathrm{PHF}$ & \\
\hline
\end{tabular}




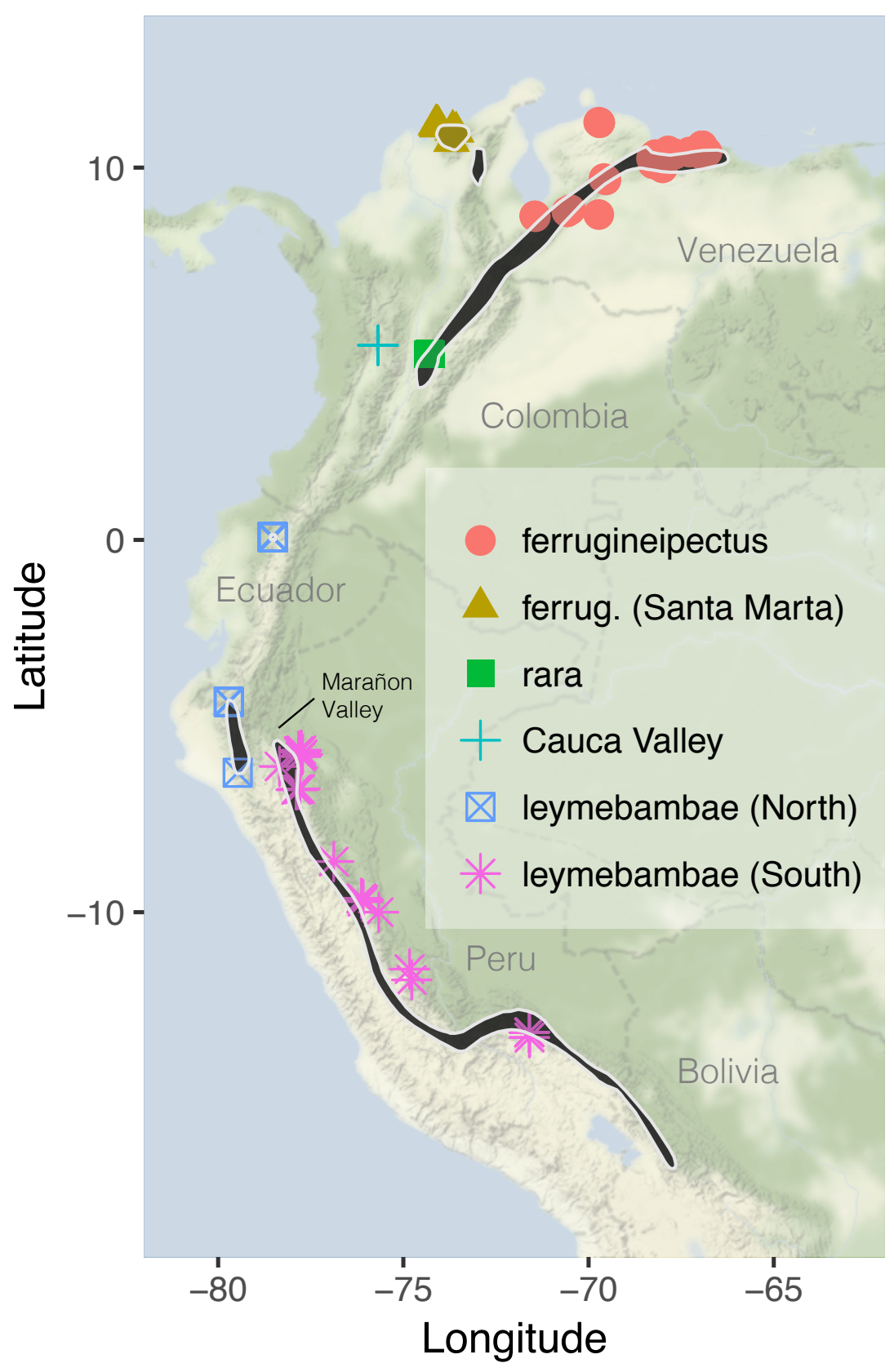

653 FIG. 1. Locations of audio recordings included in this study, colored by population. The range

654 map of this species from BirdLife International (BirdLife International and NatureServe 2015) is

655 indicated in black. Note that this map is not fully accurate (e.g., there are recordings from sites

656 outside the range indicated in black). 


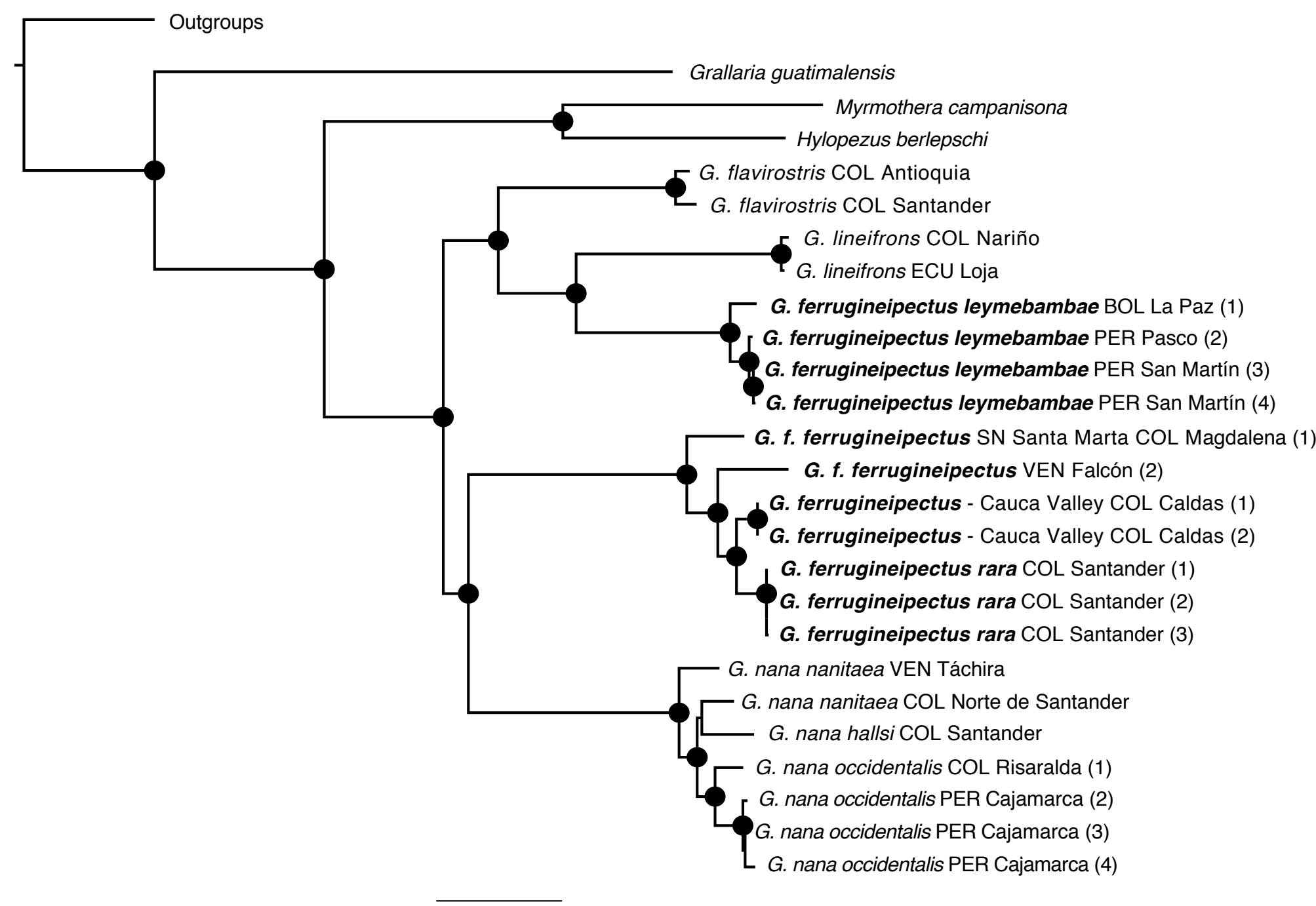

658 FIG. 2. Maximum-likelihood phylogeny of a subset of the Grallariidae. Note that Grallaricula ferrugineipectus sensu lato is

659 polyphyletic. Black circles at nodes indicate bootstrap support values $>70$ based on 999 maximum-likelihood replicates. 


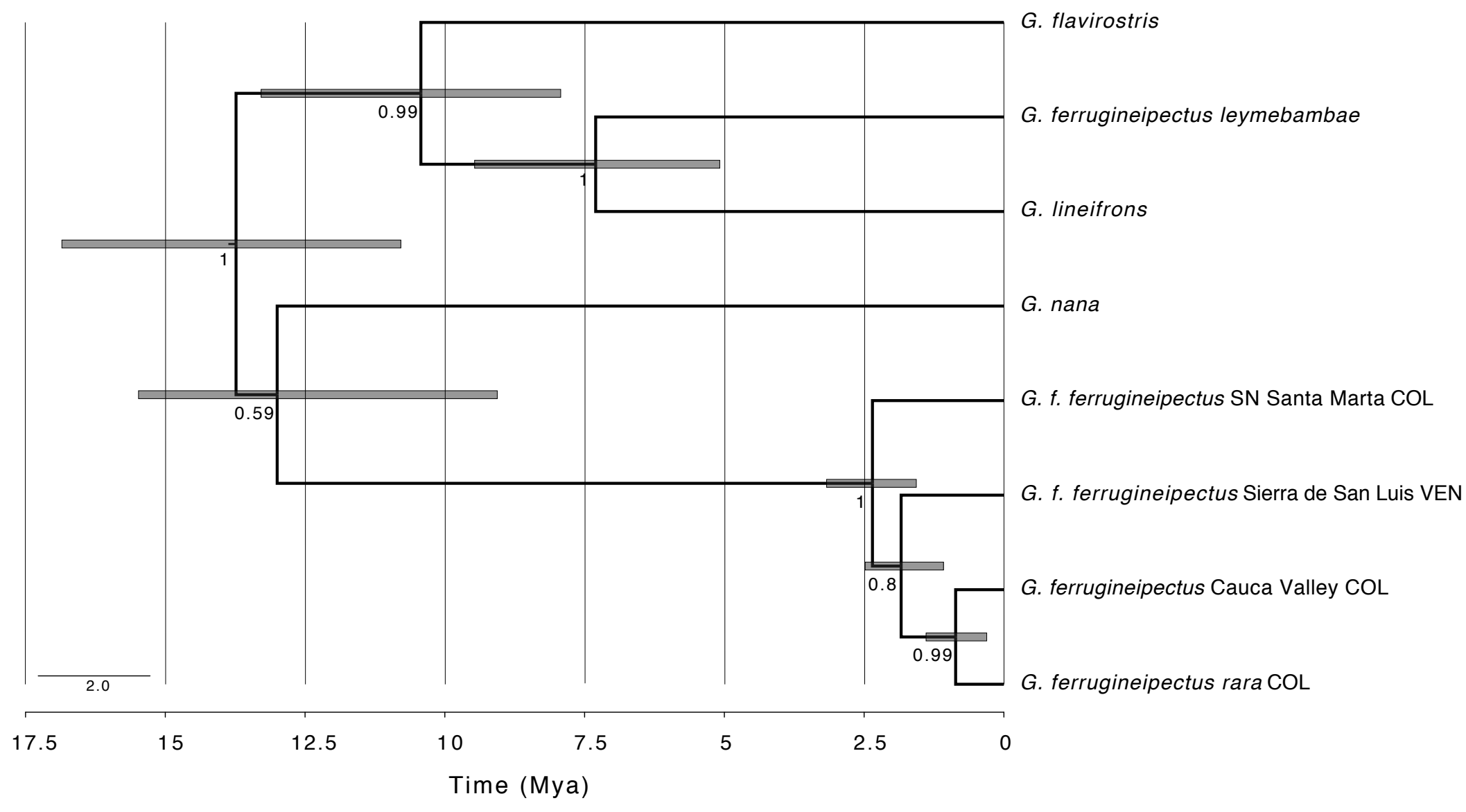

660

661 FIG 3. Bayesian estimate of phylogenetic relationships and divergence times among a subset of the Grallariidae. Grallaricula

662 ferrugineipectus sensu lato is polyphyletic; the northern and southern groups (G.f. ferrugineipectus and G. f. leymebambae) last

663 shared a common ancestor around 13 million years ago. Bars at nodes indicate the $95 \%$ highest posterior density for the inferred

664 divergence time estimates. Numbers at nodes indicate posterior probability support values. 


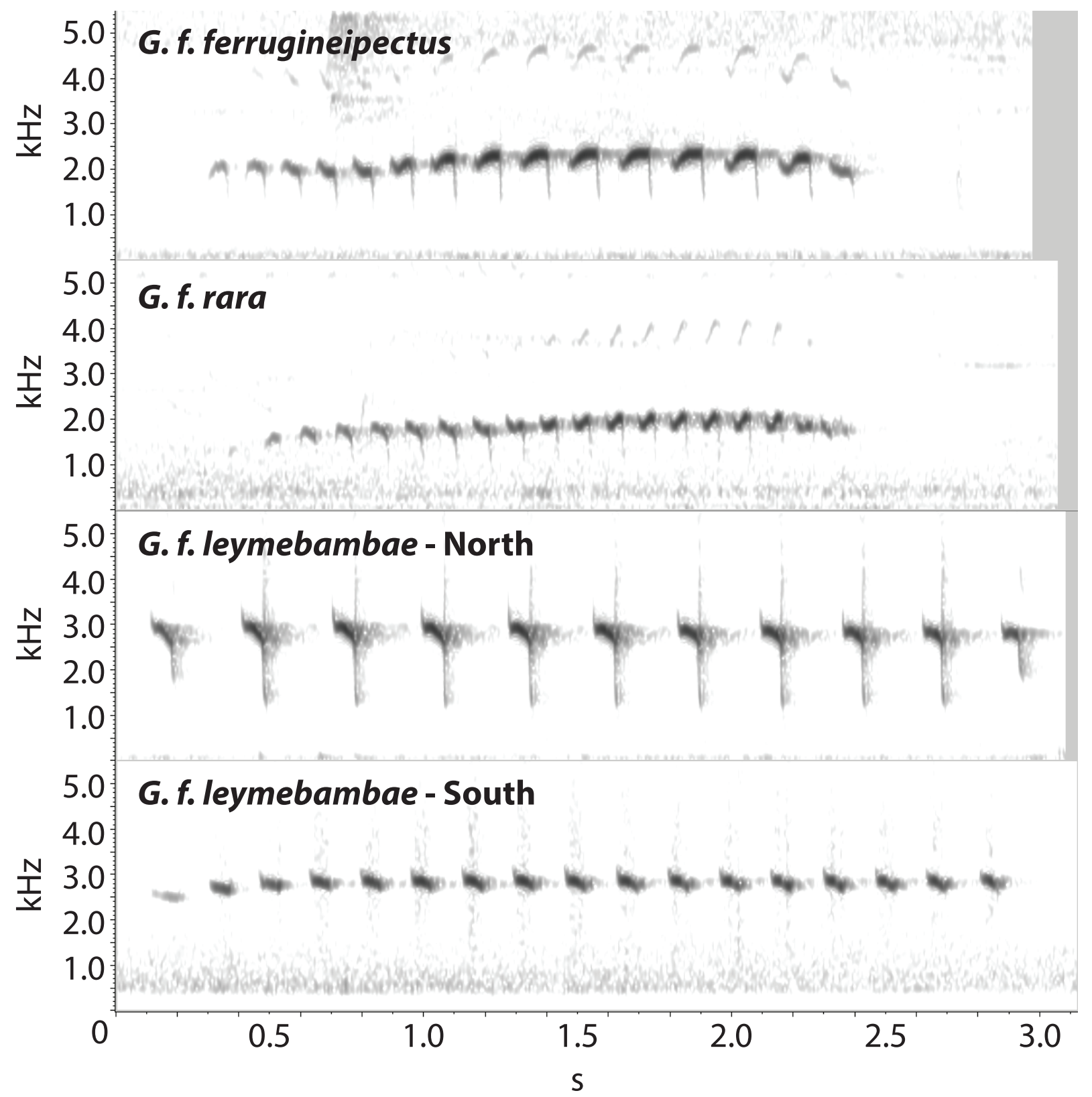

665

666

FIG. 4. Representative spectrograms of Rusty-breasted Antpitta songs. Spectrograms were made

667 in Raven Pro 1.5 with the following parameters: Hann windows of size 553 samples; hop size 668 277 samples; DFT size 1024 samples.

669 


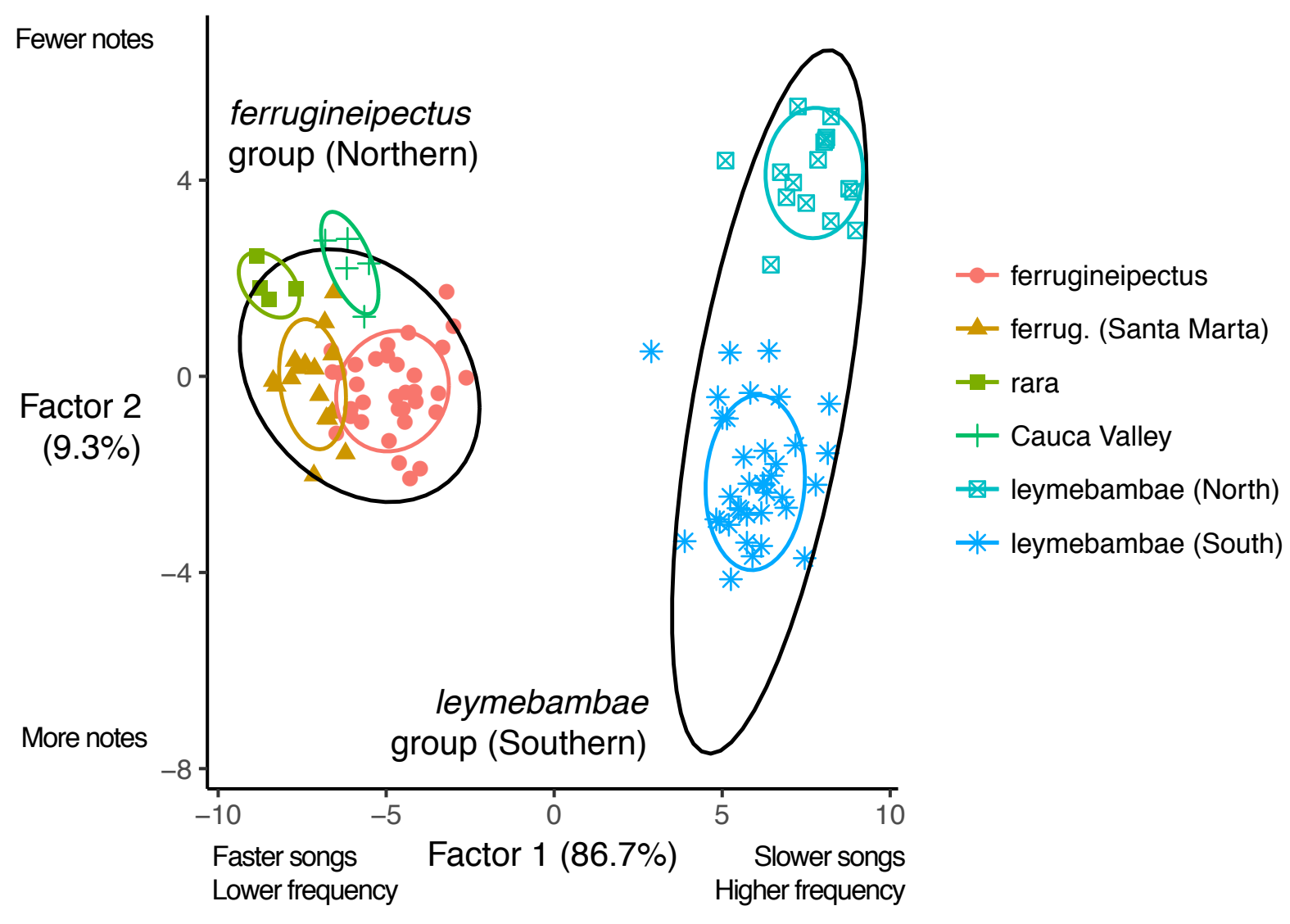

671 FIG. 5. First two factors from discriminant function analysis separating Rusty-breasted Antpitta 672 subpopulations by variation in 15 vocal traits. Black ellipses are $95 \%$ prediction ellipses for 673 northern and southern groups; colored ellipses are 75\% prediction ellipses for subspecies. 


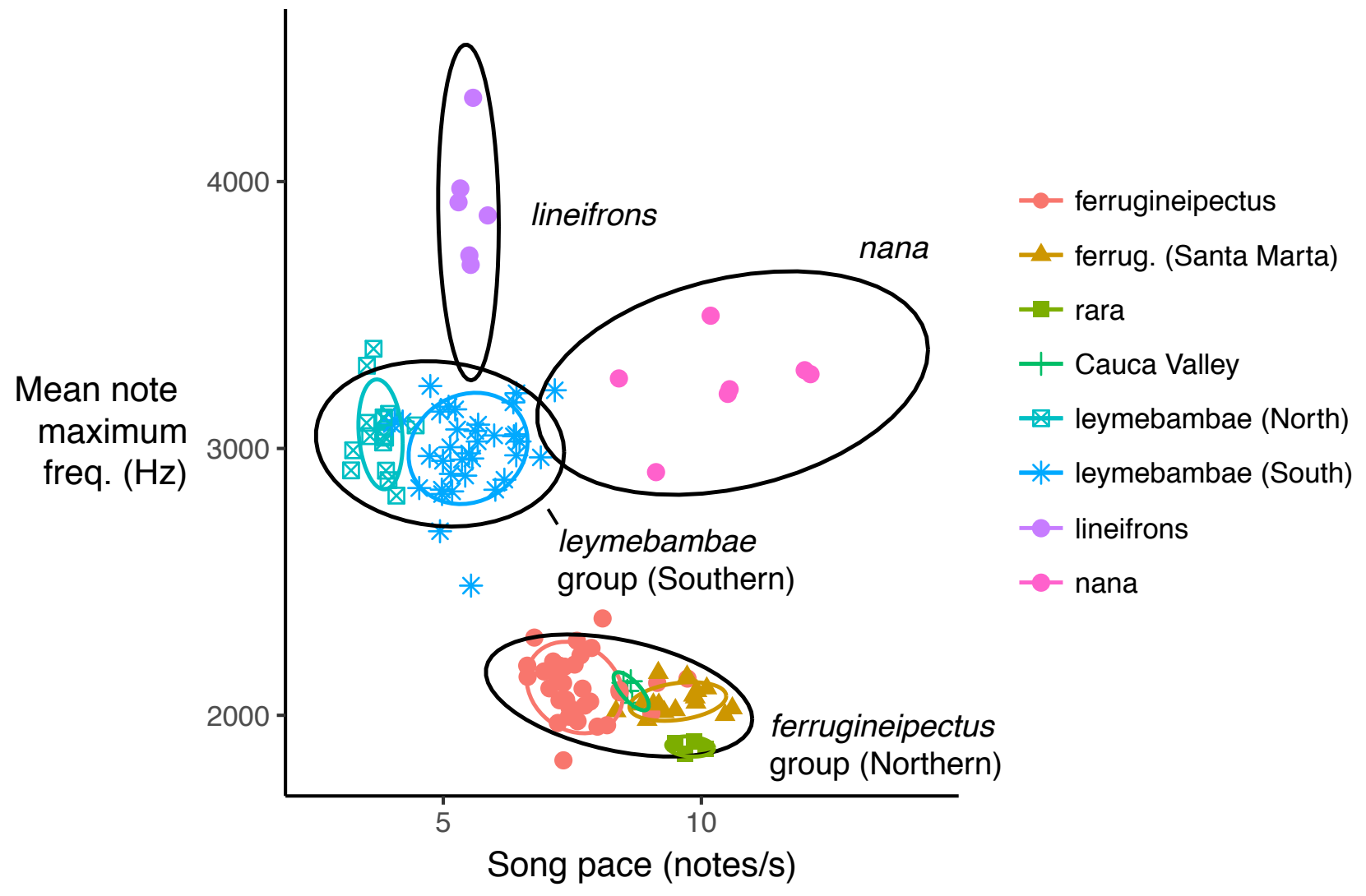

675 FIG. 6. Mean note maximum frequency versus note rate for all Rusty-breasted Antpitta

676 populations and two closely related species, G. nana and G. lineifrons. These two variables

677 generally showed the greatest differentiation across Rusty-breasted Antpittas. 


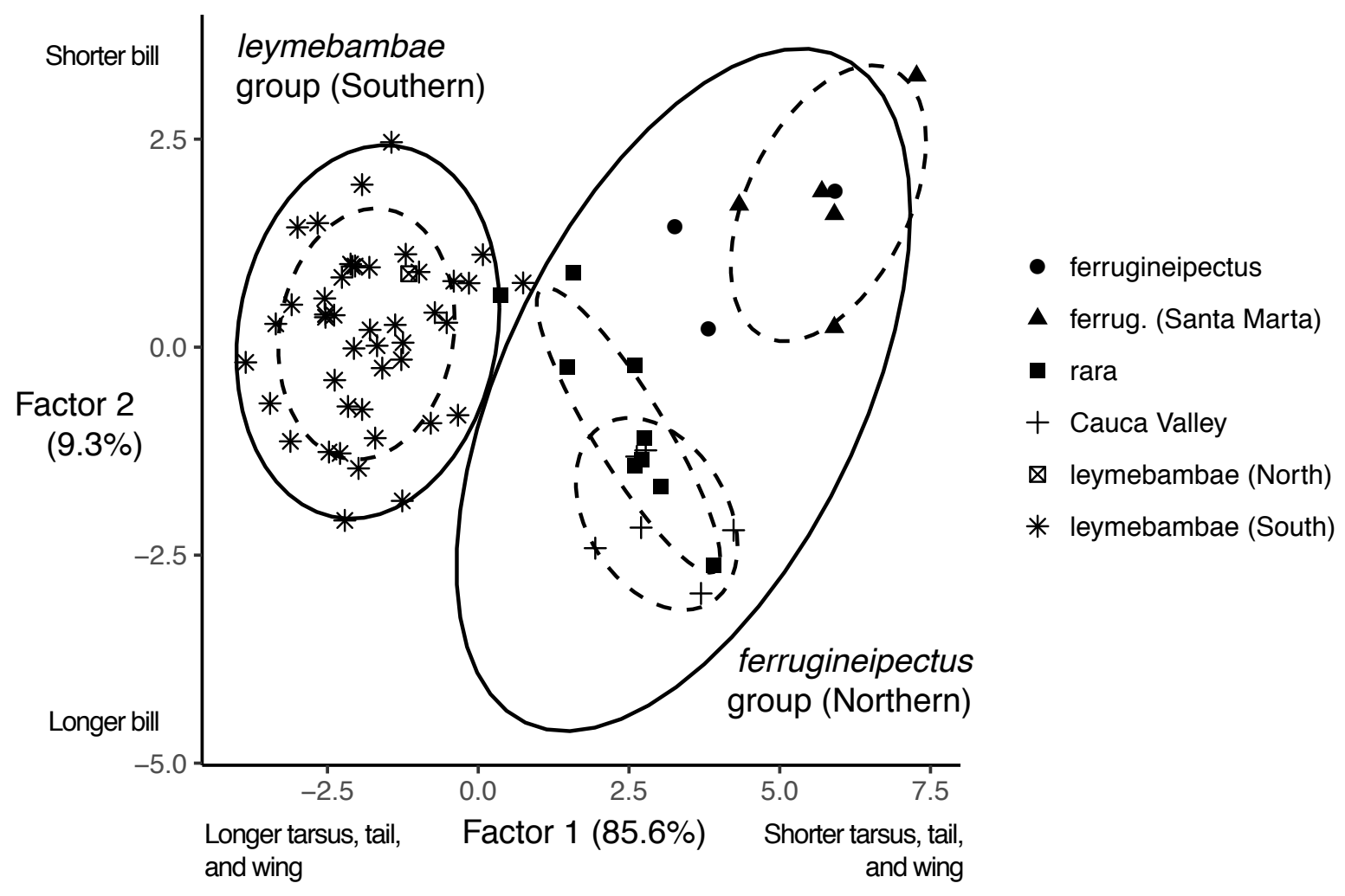

679 FIG. 7. First two factors from discriminant function analysis separating Rusty-breasted Antpitta

680 subpopulations by variation in 6 morphological traits. Black ellipses are 95\% prediction ellipses

681 for northern and southern groups; colored ellipses are $75 \%$ prediction ellipses for

682 subpopulations. 


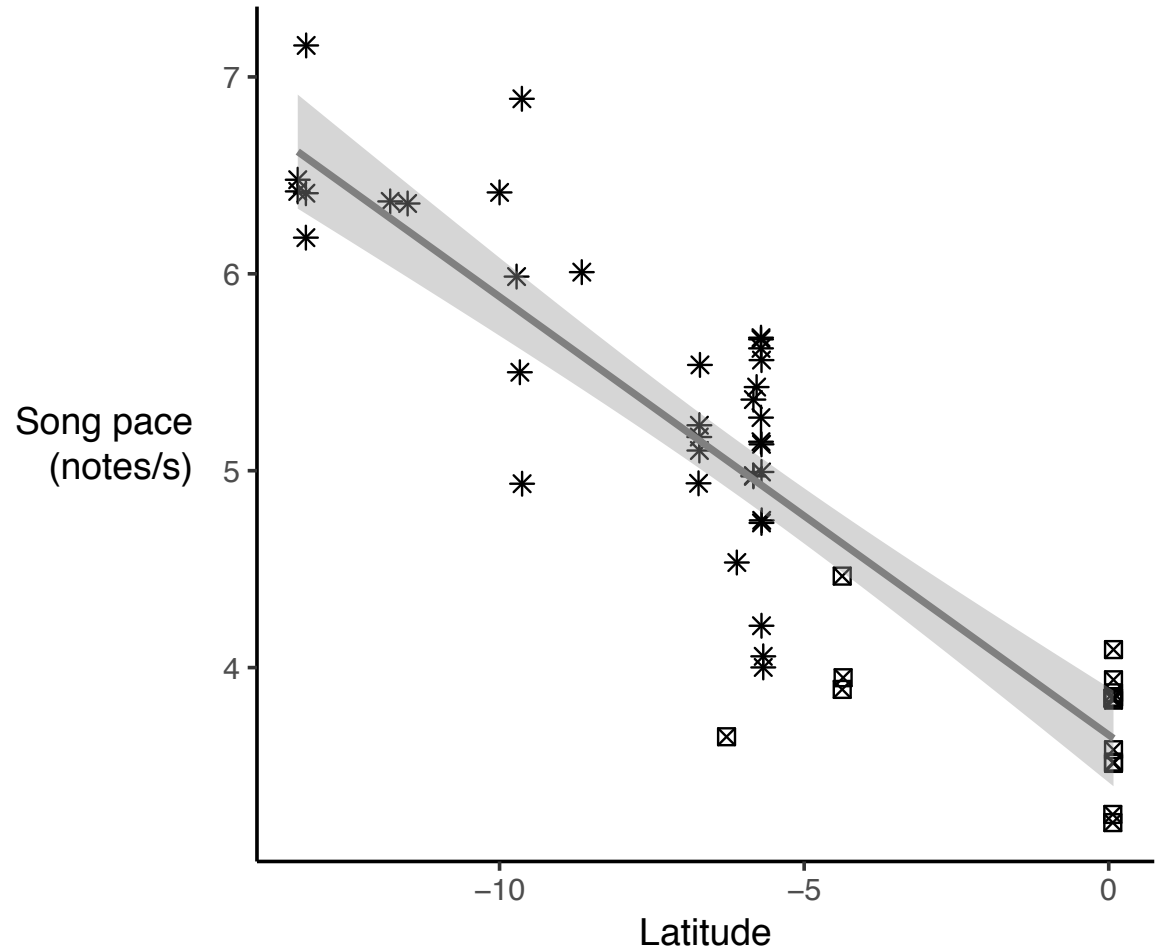

$\boldsymbol{\Delta}$ leymebambae (North)

* leymebambae (South)

684 FIG. 8. Song pace versus latitude for southern Rusty-breasted Antpittas. 